\title{
VALORES MODAIS DO MORFEMA -RA NA LÍRICA PROFANA GALEGO-PORTUGUESA
}

\author{
MODAL MEANINGS OF THE MORPHEME -RA \\ IN THE SECULAR GALICIAN-PORTUGUESE LIRIC
}

\author{
Márluce Coan | Lattes| coanmalu@ufc.br \\ Universidade Federal do Ceará
}

Resumo: Neste artigo, utilizando dados da lírica profana galego-portuguesa, analisamos os usos modais do morfema -ra no eixo passado, considerando-se seus significados de passado conjuntivo, passado condicional, passado volitivo e passado anterior ao momento de fala, bem como investigamos os efeitos do tipo de cantiga, do item lexical e da polaridade na configuração desses usos modais. Nossos dados provêm das cantigas profanas disponíveis no Tesouro Medieval Informatizado da Língua Galega e no projeto Edição, Atualização e Preservação do Património Literário Medieval Português. Os resultados apontam maior frequência modal de -ra em cantigas de amor, especialmente nas funções condicional, volitiva e conjuntiva, por vincularem-se a segredos amorosos, diferentemente das de escárnio e maldizer, que exibem um estilo mais direto. Em relação à análise lexical, nossos resultados indicam que, na função volitiva, ganham destaque os verbos modais; nas demais funções, predominam verbos de estado, cognitivos e sensitivos, em oposição aos verbos de ação e processo, mais utilizados quando o -ra codifica funções temporais. Ademais, há mais usos de -ra modal em contextos de polaridade positiva, implicando equilíbrio entre as tarefas de cognição e codificação: a expressão da irrealidade ou distanciamento da realidade via -ra é função menos frequente que a temporal, portanto, mais marcada, função codificada em contextos mais frequentes (os afirmativos), portanto, menos marcados. Decorre dessa análise a observação de que, nos usos modais do -ra, podemos aludir à irrealidade, independentemente de ser o enunciado afirmativo ou negativo.

Palavras-chave: Morfema -ra. Passado conjuntivo. Passado condicional. Passado volitivo. Passado próximo.

Abstract: In this paper we analyze data from the Galician-Portuguese secular lyric regarding the uses of morpheme -ra in past time axis, considering their modal functions, such as conjunctive past, conditional past, volitive past and closer past to the speech time, and in- 
vestigate the effects of the type of lyric song, lexical token and the polarity to configure the modal contexts. Thus, our data come from the Tesouro Medieval Informatizado da Lingua Galega and the project Edição, Atualização e Preservação do Património Literário Medieval Português. The results show a higher modal frequency of -ra in love songs, especially in the conditional, volitive and conjunctive functions by binding to love secrets as opposed to scorn and bad comments, which exhibit a more direct style. In relation to lexical analysis, our results indicate that modal verbs stand out in the volitive function, whereas in other functions predominate state, cognitive and sensitive verbs, as opposed to the action and process verbs, which are more used in the temporal functions. Furthermore, there are more uses of the modal -ra in contexts of positive polarity that means a balance between cognition and coding tasks: the expression of unreality or distance from reality by -ra is less frequent, therefore more marked than -ra with temporal function, but is codified in more frequent contexts (affirmatives), therefore less marked. From this analysis results the observation that in the modal uses of -ra, we can allude to unreality, regardless of the affirmative or negative statement.

Keywords: Morpheme -ra. Conjunctive past. Conditional past. Volitive past. Closer past.

\section{Introdução}

As cantigas trovadorescas galego-portuguesas, produzidas entre o final do século XII e meados do século XIV, desenvolvem-se nos reinos de Leão e Galiza, de Portugal e de Castela. Conforme Carolina Michaëlis de Vasconcelos, desde o extremo da Galiza até o extremo do Algarve, apesar de haver algumas variantes provinciais, há um tipo linguístico comum, além de "modos de viver, sentir, pensar, poetar" semelhantes - "uniformidade e semelhança que falam eloquentemente a favor da afinidade primitiva de lusitanos e galaicos" (VASCONCELOS, 1904, p. 780). Nesse contexto, com a criação do gênero "cantiga de amigo", o movimento trovadoresco, iniciado na França, assume características próprias.

Embora as cantigas tenham feição artística, resultem, em alguns casos, de estilizações, foram feitas com critério uniformizador (LORENZO, 1975), já que os trovadores utilizavam uma língua comum. Para Monteagudo (2012), o termo galego-português justifica-se tanto do ponto de vista histórico quanto literário, já que foram os cancioneiros galego-portugueses que registraram as mais antigas manifestações literárias do idioma, resultado da evolução natural do latim vulgar. Essa língua denominada galego-português 
ou galaico-português, conforme Teyssier (1997), já ocorria desde o século IX, no entanto, os textos escritos só aparecem no século XIII, período em que a reconquista militar e política está em vias de terminar: a língua literária que emerge então é o galego-português do Norte, forma que toma o latim no ângulo noroeste da Península Ibérica, região correspondente à parte do território que hoje é Espanhol (norte do rio Minho) e à parte que hoje é território português (sul do Minho e norte do Douro).

Castro (2002) chama-nos a atenção, também, para o fato de que, para o primeiro linguista português, Francisco Adolpho Coelho, não havia dúvida de que, na Idade Média, os dialetos galegos e portugueses divergiam muito pouco: "portuguez e gallego sahiram d'uma mesma base commum, a lingua gallecio-portugueza dos seculos XII a XIV” (COELHO, 1887, p.132 apud CASTRO, 2002, p. 7). Considerando-se que, entre os séculos XIV e XVI, acentuaram-se divergências entre galego e português, em grande parte, por razões históricas e políticas (MAIA, 1986), o estudo da lírica trovadoresca, justamente pelo critério uniformizador, poderá revelar resultados expressivos. Conforme a autora, todos os elementos, mesmo fragmentários, são preciosos para conhecermos mais sobre os dialetos da idade média. Também Monteagudo (1999) adverte que há necessidade de um estudo mais profundo da lírica galego-portuguesa, para constatar o caráter homogeneizante que é evidente no aspecto ortográfico.

Especificamente sobre o morfema -ra, tema de nossa pesquisa, Martins e Paiva (2013) observam que conclusões mais definitivas, acerca de sua trajetória e perda de produtividade em Português, exigem uma análise que considere os diferentes usos dessa desinência em estágios anteriores, principalmente, no português medieval. Optamos por analisar esses usos do -ra nas cantigas profanas, porque, diferentemente de outros gêneros, trata-se de produções que estariam, segundo Lagares (2006), entre a escrita e a oralidade, entre o erudito e o popular.

Tendo em vista que quase todas as línguas românicas (com exceção do romeno e do galego) evidenciam desenvolvimento de um mais-que-perfeito analítico (haver ou ter mais particípio) em lugar do mais-que-perfeito sintético que era único em latim, poucos linguistas, conforme Söhrman (2015), tem se dado conta de que o -ra pode expressar modalidades diferentes, que o autor resume em dois conceitos: (i) mudança do mundo referencial (quando a referência não tem enlace com um momento do mundo real, mas com um mundo possível, ou seja, não fala sobre o passado, mas de algo cognitivamente distante) e (ii) aumento da força ilocucionária (há uma força que modifica a mensagem, mas não um deslocamento ao mundo real). Ainda segundo o autor, os valores modais do 
mais-que-perfeito são bastante notáveis, embora pouco comentados.

Neste artigo, com o intuito de tratar do morfema -ra, analisamos seus valores modais na lírica trovadoresca galego-portuguesa, ou seja, em dados dos primórdios da Língua Portuguesa, tendo em vista que, por volta de 1350, conforme Teyssier (1997), esta língua galego-portuguesa do Norte, já separada por fronteira política, começa a sofrer evolução gradativa e transformar-se no português. Seguimos a premissa de que há um processo de gramaticalização em que uma forma de valor temporal passa a codificar, também, valores modais. Com esse propósito, pautamo-nos, primordialmente, em estudos funcionalistas referentes à gramaticalização, cujos pressupostos apresentamos na seção que segue.

\section{Base teórica}

Pautamos nossa análise em estudos de gramaticalização como extensão metafórica, na acepção de Bybee, Perkins e Pagliuca (1994). Os autores não restringem gramaticalização ao desenvolvimento de morfemas gramaticais a partir de lexicais; consideram outros mecanismos como: extensão metafórica; inferência; generalização; harmonia e absorção (retenção de um traço). Ademais, Heine et al. (1991) referem-se à gramaticalização como mudanças de significados baseados na situação externa para significados baseados na situação interna, em função textual ou nas crenças do falante. Em tais casos, a mudança não leva, necessariamente, à substituição, mas à estratificação (HOPPER, 1991), devido à emergência e à coexistência de camadas. Essa perspectiva de gramaticalização está assentada nas consequências do processo, o que reflete, segundo Lichtenberk (1991), a gramática como produto de um desenvolvimento histórico.

Klein-Andreu (1991) observa que o significado original de -ra tem sido reanalisado de referência a um tempo anterior, a algum ponto no passado, à referência de um passado sem indicação de anterioridade e de assertivo a não-assertivo. Em análise de dados do século XIV, especificamente do espanhol, a autora localizou 16 casos de -ra irrealis, ao passo que havia 135 de -ra realis. A utilização de -ra em eventos hipotéticos o conduziu à indicação de não-assertividade: primeiramente, observou-se o -ra em apódoses (oração consecutiva de uma condicional), depois em prótases (oração condicional), refletindo um processo de maior para menor assertividade.

Além desses usos em orações condicionais e/ou consecutivas de uma condicional, há também um uso de -ra que não tem a ver com anterioridade temporal, mas com uma estratégia modal para distanciar o falante do conteúdo proposicional. Fleischman (1989) mostra que tal uso não reflete o significado básico de tempo passado, mas reflete 
uma distância mais ampla da realidade presente. Nessa perspectiva, o uso modal do -ra pode ser analisado como uma metáfora do tempo, uma expressão atitudinal do falante/escritor relativamente ao conteúdo proposicional (FLEISCHMAN, 1982; BYBEE e FLEISCHMAN, 1995), já que, conforme Travaglia (1991), formas verbais têm uma função dêitica de localização do evento e uma função modal de indicação de realidade (função ideacional, conforme Halliday, 1985). O uso do -ra serviria, portanto, para indicar menos assertividade, distanciando o enunciador do conteúdo proposicional. Esse uso é classificado como metafórico porque uma forma que codifica distanciamento temporal é utilizada para indicar distanciamento em outros eixos cognitivos ou conceptuais (SWEETSER, 1990).

Em alusão à proposta de Givón $(1984 ; 1993 ; 2001)$, tais usos atestados na literatura representariam asserção irrealis (verdade possível), coincidindo com as noções de futuridade (possível, incerto), em contraposição à factualidade do passado. Conforme o autor, isso teria a ver com representação cognitiva dos eventos memorizados versus imaginados, o que estaria associado à tipologia verbal, por descrever mundos imaginários versus estados ou eventos, refletindo, portanto, modalidade irrealis ou realis.

Como Peréz (2017), reconhecemos a irrealidade como conteúdo gramaticalizado, associado a valores pragmáticos variados, por exemplo, cortesia, atenuação, negação implícita, improbabilidade, bem como concebemos que a irrealidade é um conteúdo modal de expressão da realidade subjetiva. Para Coan (2020), quando o -ra expressa irrealidade salienta a modalidade e não o tempo, sendo, portanto, uma metáfora da expressão do tempo. Trata-se de uma estratégia de distanciamento em outros domínios via escolha de uma forma mais distante temporalmente, o que nos leva a pressupor que, na escolha do -ra modal, também interfira a iconicidade nos termos de Givón (1990; 1991; 1995 e 2001): a codificação via forma que marca distanciamento temporal pode refletir um procedimento cognitivo para marcar distanciamento da situação expressa pela forma verbal.

Nas cantigas, de acordo com Xove (1977), a forma em -ra conserva seu valor temporal, salvo em alguns casos de modalidade irreal (poderan = poderiam) e outros de imperfeito do subjuntivo (-ra =-se). O uso "de cortesia ou de modéstia" (poderan = podiam/ poderiam), para Rojo (1974), coincide com o imperfeito ou futuro hipotético: a aparição da forma em -ra nesse tipo de frase ocorre porque se trata de orações de sentido condicional cuja prótase se há elidido; não podem, portanto, ser substituídas por -se, comutando apenas com formas do indicativo. Na acepção de Gili Gaya (1973), esse uso reflete uma zona indeterminada entre subjuntivo e indicativo. Em relação ao uso subjuntivo de -ra, 
em análise do Cancioneiro da Ajuda, Martinez e Moscoso Mato (2007) localizaram formas do tipo 'cantara' com valor de pretérito do subjuntivo (pretérito imperfeito), além do valor prototípico de antepretérito (pretérito mais-que-perfeito).

São os valores modais de -ra que nos interessam nesta pesquisa, por isso atentamos para esses usos conjuntivos e condicionais, bem como para outros dois valores atestados em estudos diacrônicos: passado volitivo e passado próximo. Coan, Lima e Sampaio (2019) e Coan (2021) atestam uso de -ra em enunciados desiderativos, nos quais há projeção de um desejo ou possibilidade. Xove Ferreiro (1977), Fiorin (1996) e Coan (2003) verificam, outrossim, que o mais-que-perfeito em -ra, às vezes, é utilizado para indicar uma ação passada anterior ao momento de fala e não anterior a outro passado. Esse uso (conforme Szertics, 1967 apud Xove, 1977) pode ser observado também no romanceiro velho castelhano.

Para operacionalizar nossa proposta e articular os dados aos pressupostos acima expostos, opções metodológicas foram necessárias, tanto em termos de confiabilidade dos dados quanto em termos de seleção dos parâmetros analíticos. Esses procedimentos integram a próxima seção, na qual (i) listamos o corpus, (ii) mostramos dados descartados, tendo em vista o foco deste artigo, e (iii) apresentamos os parâmetros analíticos. Dessa guisa, passa a ser evidente que não nos debruçamos sobre toda a lírica galego-portuguesa (profana e mariana), mas somente sobre a lírica profana; também que nos interessamos pelas funções modais, cientes de que o -ra tem domínio mais amplo; ademais, três parâmetros analíticos foram escolhidos, tendo em vista as opções teóricas delineadas acima.

\section{Procedimentos metodológicos}

Analisamos cantigas profanas provenientes de três recolhidas: o Cancioneiro da Ajuda, o Cancioneiro da Biblioteca Nacional e o Cancioneiro da Biblioteca Vaticana. Em geral, são cantigas de amor (cantigas em voz masculina), de amigo (cantigas em voz feminina) e de escárnio e maldizer (cantigas satíricas, encobertas - de escárnio ou ostensivas - de mal dizer), embora haja outras: espúrias, de sirventês moral e de gênero incerto, nas quais também localizamos dados da forma em -ra com função modal. As cantigas são do final do século XII a meados do século XIV, período em que a língua falada se desenvolve como língua literária por excelência. São 1.683 cantigas, desconsideradas aqui $A s$ Cantigas de Santa Maria. Embora tenham em comum com as cantigas profanas a língua galego-portuguesa, são fundamentalmente cantigas religiosas, cuja temática recai sempre a atos de louvor. Conforme Massini-Cagliari e Favaro (2010), tais cantigas, mandadas 
compilar por Afonso X, relatam, em geral, milagres marianos, embora haja algumas referentes a festividades (também marianas). Igualmente, Bacarat (2010) destaca que os dois gêneros predominantes nas Cantigas de Santa Maria são: cantigas de milagre (relato de acontecimentos nos quais a Virgem intervém a favor de algum personagem devoto) e cantigas de louvor (poemas líricos, nos quais D. Afonso X se revela fiel à Santa Maria).

Nossos dados provêm do TMILG (Tesouro Medieval Informatizado da Língua Galega - http://ilg.usc.gal/tmilg/) e da Base https://cantigas.fcsh.unl.pt, resultante do projeto Edição, Atualização e Preservação do Património Literário Medieval Português. O TMILG, sediado no Instituto da Língua Galega - Universidade de Santiago de Compostela, disponibiliza, aproximadamente, 16.000 unidades textuais da era medieval, distribuídas por gênero textual: a) prosa documental (aquisição e gestão patrimonial; mundo mercantil e transações comerciais; documentos administrativos; documentos familiares; escritos em geral como depoimentos, advertências, sentenças etc; documentos reais e documentos eclesiásticos); b) prosa não documental (literária, histórica, religiosa, técnica e jurídica) e c) poesia (lírica trovadoresca - profana e religiosa - e lírica da decadência). Essas 16.000 unidades compreendem o período que vai do século VIII ao XVII. O projeto LITTERA, sediado no Instituto de Estudos Medievais da Faculdade de Ciências Sociais e Humanas da Universidade Nova de Lisboa, é uma base que inclui a totalidade das cantigas medievais dos cancioneiros galego-portugueses, bem como as respectivas imagens dos manuscritos, que podem ser consultados para conferência de dados. Ademais, para as edições, a base considerou leituras anteriores de numerosos especialistas, como as de Carolina Michaëlis, Henry Lang, Oskar Nobiling, José Joaquim Nunes ou Rodrigues Lapa.

Embora os dados sejam os mesmos, nossa recolhida, inicialmente no TMILG, necessitou de confirmação interpretativa, assim, analisamos a interpretação dada pelo projeto LITTERA, bem como confirmamos outras nos manuscritos disponibilizados pelo projeto. Esse percurso, embora exaustivo, livra-nos de interpretações equivocadas tendo em vista o distanciamento temporal que, por vezes, trai nosso julgamento. Em alusão à proposta de triangulação de dados, a observação dos mesmos dados nos dois corpora dá mais confiabilidade aos resultados.

De posse dos dados em -ra, selecionamos aqueles que diziam respeito a funções modais no eixo pretérito. Dessa guisa, excluímos desta análise em particular os usos de -ra dispostos no eixo do futuro, já que há muitos exemplos cuja distinção é contextual, tendo em vista que a forma é a mesma (sem acento, para distinguir, por exemplo -ra de -rá), 
como ocorre com o exemplo (1) abaixo. Também os casos em que havia a forma -ra no corpus, mas em comparação ao manuscrito era -ro, conforme exemplo (2). Outrossim, em termos funcionais, excluímos os usos de -ra como antepretérito/passado do passado (conforme exemplo 3), cuja função é temporal e não está em foco neste artigo, no qual priorizamos as funções modais do eixo passado.

(1) E poila vir, se poder ssy guardar | de lh' aviir com' end' a min aven, | ben terrey eu que escapara en; | mays d' üa ren ei ora gram pavor: | des que a vir, este conselhador $\mid$ de non poder min nen ssy conselhar. (Martin Soarez) ${ }^{1}$

(2) Os namorados que trobam d' amor | todos deviam gram doo fazer | e nom tomar em si nem üu prazer, | por que perderan [perderon] tam boo senhor | como el rei dom Denis de Portugal, | de que nom pode dizer nem üu mal | homem, pero seja posfazador. | (Johan, jograr - jogral medieval)

(3) Deitou un frad' a pacer sas bestas, que comprara; e, por que as non achou ali u as deitara, | irado-los-á el-Rei. (Fernan Soarez de Quinhones)

Após essa seleção, mapeamos as diferentes funções modais por tipo de cantiga (amor, amigo, escárnio e maldizer, além das de espúria, sirventês moral e gênero incerto). $\mathrm{Na}$ sequência, observamos marcas modais associativas de acordo com o item lexical e com polaridade (orações afirmativas versus negativas), as quais poderiam levar ou contribuir à interpretação modal do morfema -ra. Em todas essas análises, computamos frequência de uso, considerando, a exemplo de Labov (1972), Lass (1980), Bybee (2007) e Fox (2007), a importância da frequência para a mudança e para a modulação gramatical.

\section{Análise: acepções modais do morfema-RA}

Do corpus sob análise, verificamos que há 289 dados de -ra, distribuídos em: a) acepções temporais, 97 dados (conforme ilustramos acima em 3), os quais não são objeto de estudo nesta pesquisa, e b) 192 dados com acepções modais: de passado condicional (121 dados), volitivo (32 dados), conjuntivo ( 24 dados) e próximo (15 dados), ilustradas, respectivamente de 4 a 7 abaixo. Para cada exemplo, diagramamos, conforme proposta de Reichenbach (1947), o dado sob análise e seu ponto de referência em perspectiva temporal, para mostrar que a forma em -ra (considerada aqui o momento do evento

\footnotetext{
${ }^{1}$ Os dados bem como os nomes dos autores são aqui grafados como aparecem no TMILG - Tesouro Medieval Informatizado da Língua Galega, que foi nossa primeira base de coleta dos dados.
} 
- ME) ora se situa temporalmente antes do ponto de referência que, por sua vez, situa-se antes do tempo de fala como no clássico exemplo de passado do passado: $M E>M R>M F$, porém isso nem sempre ocorre, havendo outras configurações temporais, as quais contribuem à interpretação modal de -ra. Em (5) e (6), os valores modais volitivo e conjuntivo retratam a mesma configuração temporal do -ra quando interpretado como passado do passado, imperando, portanto, à interpretação modal, outros parâmetros discursivos (por exemplo, verbo desiderativo em 5 e estrutura conjuntiva com -se em 6). Nos outros dois casos, o evento em -ra ou é posterior ao MR, como em 4, com acepção de eventualidade no passado, ou é anterior ao MF (conforme exemplo 7), com acepção de distanciamento conceptual, como veremos no decorrer da análise.

(4) Se conos cardeaes, con que faz seus conselhos, | posesse que guardasse nós de maos trebelhos, | fezera gran mercee, ca non furtar con elhos | e [os] panos dos cristäos meter sô sa capa. (Afonso X, o Sabio)

posesse/guardasse fezera

(5) Que doo que agora ey | dos meus olhos polo chorar | que faram, poy' los eu levar, | senhor, hu vos non veerey, | ca nunca os ey a partir | de chorar, hu vos eu non vyr. | Quisera-m’ eu que vyssen al | e non vissen vós estes meus | olhos e non quis assy Deus, | mays sey que mi verrá en mal, | ca nunca os ey a partir | de chorar, hu vos eu non vyr. | (Roi Fernandiz)

quisera $\quad$ vyssen

(6) Ca, sse non vyran estes olhos meus, | nen viran vós, hu vos eu fuy veer, | e, sse eu ren non soubess' entender | do mui gram ben que Deus a vós quis dar, | non averia este mal, par Deus, | por vós d'Amor, que mh-á ced' a matar, | a que me vós metestes en poder. (Martin Perez Alvin)

MEMR$\mathrm{MF}$ 
(7) E, mia dona, quen pregunta non erra; | e vós, por Deus, mandade preguntar | polos naturaes deste logar | se foderan nunca en paz nen en guerra, | ergo se foi por alg' ou por amor. | (Afons'Eanes do Coton)

foderan $\quad$ mandade

Classificamos como condicionais os dados com acepção de futuro do pretérito, como o do exemplo (4), porque indica uma eventualidade ou hipótese que seria satisfeita se o fosse aquilo que a condiciona, assim: guardando > faz; se guardasse > faria; não guardando > não faz. Em (5), ilustramos o uso volitivo: trata-se de um desejo, de uma pretensão, mas não condicionada, como no caso anterior. Embora o objeto do desejo não seja satisfeito, o desejo permanece; configura-se como um uso subjetivo, em geral ligado às aspirações do indivíduo. O pressuposto da prótase pode ser negativo, mas o da apódose é positivo. O uso conjuntivo (em 6) está ao revés do uso condicional: trata-se de premissa para que algo ocorra, assim a irrealidade da prótase implica a irrealidade da apódose, dado no qual se depreende leitura contrafactual: "se não viran" = viram; "non averia" = há. $\mathrm{O}$ dado (7) refere-se ao uso metafórico do distanciamento: opta-se por uma forma em -ra, caracterizada como forma de codificação do antepretérito (passado do passado), portanto mais distante no tempo, para codificar uma situação próxima temporalmente, embora distante conceptualmente.

Essas funções foram categorizadas de acordo com três parâmetros, tipo de cantiga, item lexical e polaridade. Vejamos primeiramente a distribuição das funções por tipo de cantiga na tabela (1). Consideramos os três maiores tipos: escárnio/maldizer, amor e amigo e amalgamamos, sob o rótulo "outras", três casos que ocorrem em três outras cantigas: espúria, de tensão e de gênero incerto. As cantigas de amor (em voz masculina) são as que mais mostram dados modais em -ra nas funções condicional, volitiva e conjuntiva. Também para a expressão de passado anterior ao momento de fala, -ra ocorre com frequência nas cantigas de amor, porém há proximidade com os usos atestados nas cantigas de amigo. Os usos condicionais de -ra nas cantigas de amor podem estar vinculados ao tópico 'segredo amoroso', conforme observa Martínez (2007), salvaguardando a intimidade dos amantes, contrariamente ao que ocorre nas cantigas de escárnio e maldizer, as quais exibem um estilo mais sincero. 
Tabela 1 - Distribuição das funções modais de -ra

por tipo de cantiga na lírica profana galego-portuguesa

\begin{tabular}{|l|l|l|l|l|}
\hline $\begin{array}{l}\text { Função } \rightarrow \\
\text { Tipo de cantiga } \downarrow\end{array}$ & $\begin{array}{l}\text { Passado } \\
\text { próximo }\end{array}$ & $\begin{array}{l}\text { Passado } \\
\text { conjuntivo }\end{array}$ & $\begin{array}{l}\text { Passado } \\
\text { condicional }\end{array}$ & $\begin{array}{l}\text { Passado } \\
\text { volitivo }\end{array}$ \\
\hline Escárnio/maldizer & 3 & 5 & 28 & 9 \\
\hline Amor & 5 & 14 & 75 & 15 \\
\hline Amigo & 6 & 4 & 17 & 8 \\
\hline Outras & 1 & 1 & 1 & 0 \\
\hline Totais & 15 & 24 & 121 & 32 \\
\hline
\end{tabular}

Fonte: elaborada pela autora.

Considerando-se, com base em Xavier (2009), que a maior parcela de mudança é atribuída ao léxico e sua vitalidade constitui o aspecto mais marcante da variação sincrônica, averiguamos quais eram os itens lexicais mais frequentes nos quais o morfema -ra possuía acepção modal. Esperava-se que os itens lexicais mais utilizados fossem aqueles referentes ao âmbito modal e cognitivo, pelo fato de, em Português, ser a forma -ra, atualmente, mais utilizada em contextos modais que temporais, conforme atestam Coan (2003) e Brocardo (2010), que sugerem um processo metafórico de expressão de situações em espaço real para situações do campo psicológico (do desejo, da pretensão), processo que tem guiado mudanças semânticas (SWEETSER, 1990). Também Coan (2021), em análise de prosa histórica, literária e religiosa da era medieval, verificou que verbos cujo lexema indica dinamicidade estariam mais para as funções temporais, ao passo que lexemas modais e estativos estariam acoplados a funções modais. Conforme Lagares (2006), a comparação das cantigas com outros dados da mesma época afasta a observação de que a língua das cantigas é uma variedade artificial, embora tenha, obviamente, características retóricas peculiares.

Nossos resultados, expostos na tabela (2), indicam que, na função volitiva, de fato, ganham destaque os verbos modais, função em que o -ra tem evidência no português oral atual. Parece que a atual disposição de usos do mais-que-perfeito (em -ra) reflete frequência de uso em outras épocas, comprovando a premissa laboviana de que um sistema em evolução reflete uma série de reajustes anteriores (LABOV, 2010). Também observamos que há considerável incidência desses usos modais com verbos de estado. Em relação ao reflexo desses usos em estágios mais atuais, podemos citar a pesquisa de Coan (2020), que observa, em contexto conjuntivo, variedade menor de lexemas verbais, destacando-se os verbos de estado (fora) tanto em orações condicionais como em comparativo-condicionais, respectivamente, com conectivos 'se' e 'como se', reforçando a carga irrealis. 
Tabela 2 - Distribuição das funções modais de -ra por lexema verbal na lírica profana galego-portuguesa

\begin{tabular}{|c|c|c|c|c|}
\hline $\begin{array}{l}\text { Função } \rightarrow \\
\text { Item lexical base } \downarrow\end{array}$ & $\begin{array}{l}\text { Passado } \\
\text { próximo }\end{array}$ & \begin{tabular}{|l} 
Passado \\
conjuntivo
\end{tabular} & $\begin{array}{l}\text { Passado } \\
\text { condicional }\end{array}$ & $\begin{array}{l}\text { Passado } \\
\text { volitivo }\end{array}$ \\
\hline achar (atopar) & - & 1 & - & - \\
\hline andar & - & - & 1 & - \\
\hline arder & - & - & 2 & - \\
\hline cuidar & - & - & 5 & - \\
\hline comprir (satisfazer) & - & - & 1 & - \\
\hline dar & - & 1 & 1 & - \\
\hline dever & - & - & 4 & - \\
\hline dizer & - & - & 1 & - \\
\hline fazer & - & - & 10 & - \\
\hline ficar & - & 1 & - & - \\
\hline filhar (tomar) & - & 1 & - & - \\
\hline foder & 1 & - & - & - \\
\hline guardar & - & - & 2 & - \\
\hline haver & - & 1 & 15 & 2 \\
\hline leixar (deixar) & - & - & 1 & - \\
\hline matar & - & - & 2 & - \\
\hline morrer & 1 & 4 & 4 & - \\
\hline mostrar & - & - & 1 & - \\
\hline nascer & - & - & 1 & - \\
\hline negar & - & - & 1 & - \\
\hline partir & 1 & - & 4 & - \\
\hline pedir & 1 & - & - & - \\
\hline pensar & - & - & 1 & - \\
\hline pesar & - & - & 1 & - \\
\hline poder & 2 & 1 & 14 & 2 \\
\hline por & 2 & - & 1 & - \\
\hline prouguer (agradar) & - & - & 1 & - \\
\hline querer & 1 & 2 & 4 & 25 \\
\hline semelhar & - & - & 1 & - \\
\hline ser & 4 & 1 & 24 & - \\
\hline trobar (trovar) & - & 1 & & - \\
\hline valer & - & - & 10 & 3 \\
\hline ver & 2 & 7 & 2 & - \\
\hline vingar & - & - & 1 & - \\
\hline viver & - & 3 & 5 & - \\
\hline Totais & 15 & 24 & 121 & 32 \\
\hline
\end{tabular}

Fonte: elaborada pela autora. 
Depois dessas duas primeiras etapas, com vistas a mostrar em que âmbito temático os valores modais de -ra mais se encaixavam, bem como com que lexema verbal eram codificados, passamos à terceira etapa em que correlacionamos os valores modais à polaridade, tendo em vista que a literatura sobre o tema observa frase negativa como contexto preferencial de uso do mais-que-perfeito nas funções modais (BECKER, 2008; BROCARDO, 2012 e COAN, 2021).

Com base em Givón $(1995 ; 2001)$, consideramos frase negativa como um contexto marcado em relação à frase positiva, já que contextos negativos são menos frequentes do que os afirmativos. Paralelamente, sendo as funções modais do -ra menos frequentes do que as temporais na era medieval, espera-se que haja mais uso modal em estruturas negativas, por atuação do princípio da marcação. Essa expectativa, no entanto, desfaz-se porque, com exceção do passado conjuntivo, em que há proximidade de usos (conforme tabela 3), nas demais funções, o -ra modal ocorre preferencialmente em contextos afirmativos, comprovando a premissa de Dubois e Votre (2012) acerca do princípio da expressividade retórica, pois, em muitas situações, uma forma marcada ocorre em contexto não marcado e vice-versa, equilibrando-se, portanto, as tarefas de cognição e codificação. A atuação desses princípios foi observada também por Coan (2020) em análise de dados de revistas históricas: tendência à atuação do princípio da marcação no uso de -ra em orações condicionais, já que foram localizados mais dados de condicionais negativas; no entanto, em se tratando das comparativo-condicionais (como se), a autora verificou equilíbrio cognitivo-contextual, pois o uso do -ra ocorreu somente em orações de polaridade positiva.

Tabela 3 - Distribuição das funções modais de -ra por polaridade na lírica profana galego-portuguesa

\begin{tabular}{|l|l|l|l|l|}
\hline $\begin{array}{l}\text { Função } \rightarrow \\
\text { Polaridade } \downarrow\end{array}$ & $\begin{array}{l}\text { Passado } \\
\text { próximo }\end{array}$ & $\begin{array}{l}\text { Passado } \\
\text { conjuntivo }\end{array}$ & $\begin{array}{l}\text { Passado } \\
\text { condicional }\end{array}$ & $\begin{array}{l}\text { Passado } \\
\text { volitivo }\end{array}$ \\
\hline Afirmativa & 10 & 13 & 91 & 31 \\
\hline Negativa & 5 & 11 & 30 & 1 \\
\hline TOTAL & 15 & 24 & 121 & 32 \\
\hline
\end{tabular}

Fonte: elaborada pela autora.

Embora a polaridade revele contextos preferenciais de uso do -ra de acordo com o princípio da marcação ou com o princípio da expressividade, essa revelação diz respeito à codificação e não necessariamente à interpretação de irrealidade, já que, independente- 
mente de ser o enunciado afirmativo ou negativo, podemos aludir à irrealidade: a negação explícita, portanto, não anula a negação implícita procedente da irrealidade (PÉREZ, 2017). Há que se considerar, ainda, que, conforme a autora, a negação externa serve ao realce expressivo; trata-se de usar a negação explícita para intensificar a implícita, ou seja, o enunciado pode expressar níveis de improbabilidade, embora a negação implícita já seja conteúdo prototípico da irrealidade.

A negação implícita não supõe mera inversão de polaridade, mas adiciona um significado de improbabilidade. Para Pérez (2017), a probabilidade pode afetar um enunciado de polaridade afirmativa ou negativa, mas não se trata de negação da probabilidade, somente se indica que algo não sucede ou é duvidoso. Observem-se os enunciados: Ele tem 5 anos. Ele não tem 5 anos ainda. Se tivera 6 anos, saberia ler. Pérez considera as duas primeiras como asserções puras (afirmativa e negativa), mas a terceira é uma asserção modalizada, pois a irrealidade é interpretada como improbabilidade, não necessariamente como inversão de polaridade (não tem 6 anos ainda; não sabe ler). Adverte a autora que, em geral, as formas expressam elevada improbabilidade ou somente improbabilidade, não se confundindo, portanto, com inversão de polaridade.

Para esclarecer o exposto, vejamos, inicialmente, como a negação implícita atua em dados de -ra conjuntivo. Em (8), trobára insere-se em uma oração afirmativa, mas reflete negação implícita, já que não trovou em algum tempo (entom = naquele tempo), portanto não se vingou do que ouviu. Em (9), vyra é antecedido de negação (non), sendo a negação explícita um indicativo de que ocorreu o oposto, mas o enunciador atua no campo das probabilidades.

(8) E sempre m' eu mal acharei | porque lh' eu entom nom trobei; | ca se lh' entom trobára ali | vingára-me do que lh' oi. (Don Denis)

(9) [É] esta coyta, que mh a morte ten | tan chegada, que non lh' ey de guarir, | ca non sei eu logar hu lhe fogir | e por esto podedes creer ben | que mi valera muy mais non veer | eu vós nen al, quando vos fuy veer, |Ca, sse non vyra, podera viver | e meor coita ca sofro sofrer. (Martin Perez Alvin)

Nos dados de -ra condicional, estamos no âmbito das suposições, mantendo-se, como nos casos de -ra conjuntivo, a negação implícita, já que a condição não foi satisfeita. A inversão de polaridade igualmente se aplica a esses casos. $O$ que se ressalta é a probabilidade de algo ocorrer, se uma condição for satisfeita. Assim, em (10), a inver- 
são de polaridade leva-nos a concluir que alguém partiu, no entanto, uma vez satisfeita a condição do perdão, não partiria. Decorre disso que um enunciado afirmativo com -ra modal condicional implica negação implícita: se lh'eu perdoass'ali / [...] s'el partira d'aqui = não lhe perdoei, não partiu. $\mathrm{O}$ mesmo vale para um enunciado negativo, já que há uma negação implícita da negação explícita: se lh'eu perdoass'ali / nunca s'el partira d'aqui = não lhe perdoei, partiu, ou seja, nega-se implicitamente uma situação negada explicitamente.

(10) sempre m' en mal acharei, | por que lh' enton non perdoei, | ca, se lh' eu perdoass' ali, | nunca s' el partira d' aqui; | que lhi perdoasse, non quix, | e fiz mal, por que o non fiz. (Estevan Travanca)

Pérez (2017) observa que, quando a referência é futura, a irrealidade costuma expressar improbabilidade em vez de negação implícita, já que não se pode parafrasear invertendo a polaridade do enunciado (quisera > não quisera). Isso se aplica à função volitiva, como em (11), pois quisera indica improbabilidade de ocorrência de algo, ou seja, parece que o enunciador objetiva evidenciar um provável desejo: "quisera da vaca despender".

(11) ...e Don Fagundo todo se messou, | por que matou sa vaca o Cajon. | Quisera-x’' el da vaca despender | tanto per que non leixass' a pacer; | ca, se el cuidasse sa vaca perder, | ante xa der'a, assi non; | e Don Fagundo quer ora morrer, | por que matou sa vaca o cajon. (Afons'Eanes do Coton)

Quanto ao passado próximo, ilustrado em (12), a perspectiva é distinta, pois o objetivo não é caracterizar irrealidade, mas uma realidade distante. Trata-se de um tipo de metáfora, se aludimos à teoria da metáfora conceptual (LAKOFF; JOHNSON, 1980; SWEETSER, 1990), que corresponde ao mapeamento de conceitos distintos. Para Moura (2007), “as metáforas não são produtos ad hoc” (p. 448); "há regularidades composicionais que agrupam categorias segundo certa lógica” (p. 449). O -ra do exemplo é forma representativa do mais-que-perfeito e não do perfeito, que à época era codificado com '-ro'. Conforme Maia (1986), em geral, o que ocorria era variação entre -ã/-an/-am para o mais-que-perfeito, diferindo-se das formas de P6 do pretérito perfeito, que terminavam, normalmente, em -õ/-on/-om (este último menos frequente), embora haja alguns casos de - u/-um. Essa forma em -ra, em (12), acopla-se ao momento de fala como ponto de 
referência, servindo para codificar distanciamento modal, assim o distanciamento temporal é conceptualmente interpretado como distanciamento em outro eixo conceptual, o modal (SWEETSER, 1990).

(12) Quantos oge no mundo son, | nen foran, nen jamais seran, | nunca quiseron, nen querran, | nen queren tan gran ben molher | com' eu vus quer'; e non me val | contra vos nen esto, nen al. (Nuno [Monio] Fernandez de Mirapeixe)

Observando pesquisas diacrônicas, verificamos que esse uso que atestamos nas cantigas perdurou na língua para codificar distanciamento da situação, uso que, conforme Coan (2003), decresce com o passar do tempo, ou seja, há mais dados dessa função nos primeiros séculos analisados pela autora (XVI a XVIII) e poucos nos séculos XIX e XX. Xove (1977) já havia observado tal uso, também, na língua literária do final do século XVIII. Citamos ainda Coan, Lima e Sampaio (2019), que verificaram decréscimo desse uso em análise de dados escritos de 1887 a 2012. Mais atualmente, essa possibilidade de uso é registrada por Cunha e Cintra (2008) com o matiz de atenuação de uma afirmação ou pedido, registro também feito por Fiorin (1996), que mostra que o mais-que-perfeito pode ser utilizado pelo perfeito, para conferir distanciamento da situação.

\section{Considerações finais}

Para que o domínio funcional modal do morfema -ra fosse mais bem dimensionado, analisamos sua distribuição por tipo de cantiga, evidenciando uso modal mais frequente nas cantigas de amor. Também mapeamos os itens lexicais de base, comprovando frequência de uso no domínio dos verbos modais e de estado, respectivamente para as funções volitiva e conjuntiva. A função volitiva é a que ainda comporta usos de -ra na oralidade (especificamente com verbos como "quisera" e "pudera"), evidenciados já na lírica profana. Ainda consideramos polaridade, porém, inversamente ao observado na literatura referentemente a outros corpora, os usos modais nas cantigas têm polaridade positiva, o que não indica factualidade, mas irrealidade. A polaridade negativa serve ao realce expressivo; trata-se de usar a negação explícita para intensificar a implícita, ou seja, o enunciado pode expressar níveis de improbabilidade, embora a negação implícita já seja conteúdo prototípico da irrealidade.

Esses resultados estão alinhados aos observados por Coan (2021), em análise de dados de prosa literária, histórica e religiosa também do galego-português, pesquisa na 
qual foi verificado uso de -ra também nas funções modais conjuntiva, condicional e volitiva, considerando-se a existência de camadas funcionais. Notou, também, a autora que é na prosa literária que mais ocorrem as funções modais, gênero no qual há mais situações vinculadas ao desejo, às projeções e às possibilidades. Ademais, observou predominância de verbos modais na função volitiva e de verbos de estado nas funções conjuntiva e condicional. Assim, tanto na prosa quanto nas cantigas, há tendências similares.

Retomando Maia (1986) e Monteagudo (1999), que mostraram a necessidade de estudos mais aprofundados sobre a lírica galego-portuguesa, para além dos ortográficos, nossa análise proporcionou uma ótica diferenciada, mais atrelada à função do que à forma. Para além do uso temporal como antepretérito (passado do passado), tão evidenciado na literatura sobre o tema, destacamos, nesta pesquisa, outras quatro funções do -ra no domínio modal: conjuntiva, condicional, volitiva e de passado relativo ao momento da enunciação.

\section{Referências}

BARACAT, M. C. B. M. O particípio passado com verbos auxiliares nas Cantigas de Santa Maria (galego-português do século XIII). Tese (Doutorado) - Programa de Pós-Graduação em Letras da Pontifícia Universidade Católica de Minas Gerais. Belo Horizonte, 2010.

BECKER, M. From temporal to modal: divergent fates of the Latin synthetic pluperfect in Spanish and Portuguese. In: DETGES U.; WALTEREIT R. The Paradox of Grammatical Change: perspectives from romance. Amsterdam: John Benjamins, 2008. p. 147-180.

BROCARDO, M. T. Portuguese pluperfect: elements for a diachronic approach. Linguistic Studies. Lisboa, v. 5, p.117-130, 2010.

BROCARDO, M. T. “O 'passado do passado' - alguns dados para a história do pretérito mais-que-perfeito em português”. Verba Hispanica, XX/1, p. 33-48, 2012.

BYBEE, J. Frequency of use and the organization of language. Oxford: Oxford University Press, 2007.

BYBEE, J.; FLEISCHMAN, S. Modality in grammar and discourse. Amsterdam, Philadelphia: John Benjamins Publishing Co, 1995.

BYBEE, J.; PERKINS, R.; PAGLIUCA, W. The Evolution of Grammar: Tense, Aspect, and Modality in the languages of the world. Chicago-USA: The University of Chicago Press, 1994.

CASTRO, I. Galegos e Mouros: A língua galega vista pelos filólogos portugueses. Conferência proferida no Congresso dos 25 anos do Instituto da Língua Galega, Santiago de Compostela. Publicado: Lisboa, Colibri/Cátedra de Estudos Galegos da Universidade de Lisboa, 2002. 
COAN, M. As categorias Tempo, Aspecto, Modalidade e Referência na significação dos pretéritos mais-que-perfeito e perfeito: correlação entre função(ões)-forma(s) em tempo real e aparente. Tese (Doutorado em Linguística) - Programa de Pós-Graduação em Linguística, Universidade Federal de Santa Catarina, 2003.

COAN, M.; LIMA, E. V.; SAMPAIO, M. F. Um retrato do pretérito mais-que-perfeito de 1887 a 2012. D.E.L.T.A., 35-2, p.1-26, 2019.

COAN, M. Obsolescência ou persistência: o mais-que-perfeito conjuntivo. Lingüística ALFAL, v. 36, n. 1, jun., p. 9-32, 2020.

COAN, M. Funções do pretérito mais-que-perfeito simples em textos literários, históricos e religiosos do galego-português. Studia Romanica et Anglica Zagrabiensia, 2021 (no prelo).

CUNHA, C.; CINTRA, L. Nova Gramática do Português Contemporâneo. 5. edição. Rio de Janeiro: Lexikon, 2008.

DUBOIS, S.; VOTRE, S. J. Análise modular e princípios subjacentes do funcionalismo linguístico. In: VOTRE, S. J. A construção da gramática. Niterói: Editora da UFF, 2012.

FIORIN, J. L. As Astúcias da Enunciação: as categorias de pessoa, espaço e tempo. São Paulo: Ática, 1996.

FLEISCHMAN, S. The future in thought and language. New York: Cambridge University Press, 1982.

FLEISCHMAN, S. Temporal Distance: A basic linguistic metaphor. IN: VERHAAR, J. W. M. Studies in Language. Amsterdam: John Benjamins Publishing Co, 1989. p. 1-50.

FOX, B. A. Principles shaping grammatical practices: an exploration. Discourse Studies, v. 9, p. 299-318, 2007.

GILI GAYA, S. Curso superior de sintaxis española. Biblograf, Barcelona, 1973.

GIVÓN, T. A functional-typological introduction. v. I. Amsterdam/Philadelphia: John Benjamins Publishing Co., 1984.

GIVÓN, T. Syntax - A functional - typological introduction. v. II. Amsterdam/Philadelphia: John Benjamins Publishing Co., 1990.

GIVÓN, T. Functionalism and grammar: a prospectus. University of Oregon, 1991.

GIVÓN, T. English Grammar: a functional-based introduction. v. I-II. Amsterdam/ Philadelphia: John Benjamins Publishing Co., 1993.

GIVÓN, T. Functionalism and Grammar. Amsterdam/Philadelphia: John Benjamins Publishing Co., 1995.

GIVÓN, T. Syntax: an introduction. v. I-II. Amsterdam/Philadelphia: John Benjamins, 2001.

HALLIDAY, M. A. K. An Introduction to Functional Grammar. Baltimore: Edward Arnold, 1985. 
HEINE, B.; HÜNNEMEYER, F. From Cognition to Grammar: Evidence from African Languages. In: TRAUGOTT, E.; HEINE, B. Approaches to grammaticalization. Amsterdam/Philadelphia: John Benjamins Publishing Co., 1991.

HOPPER, P. J. On Some Principles of Grammaticization. In: TRAUGOTT, E.;HEINE, B. Approaches to grammaticalization. Amsterdam/Philadelphia: John Benjamins Publishing Co., 1991.

KLEIN-ANDREU, F. Losing ground: A discourse-pragmatic solution to the history of -ra in Spanish. In: FLEISCHMAN, S.; WAUGH, L. Discourse Pragmatics. London: Roukedge, p.164-178, 1991.

LABOV, W. Sociolinguistic patterns. Philadelphia: University of Pennsylvania Press, 1972.

LABOV, W. Principles of linguistic change: cognitive and cultural factors. Oxford: WileyBlackwell, 2010.

LASS, R. On explaining language change. New York: Cambridge, 1980.

LAGARES, X. C. Uma aproximação à "língua" das cantigas galego-portuguesas. Revista Galega de Filoloxía, v. 7, p. 95-116, 2006.

LAKOFF, G.; JOHNSON, M. Metaphors we live by. Chicago: Chicago University Press, 1980.

LICHTENBERK, F. On the Gradualness of Grammaticalization. In: TRAUGOTT, E.; HEINE, B. Approaches to grammaticalization. Amsterdam/Philadelphia: John Benjamins Publishing Co., 1991.

LORENZO, R. Gallego y Portugués. Algumas semejanzas y diferencias. In: NAVARRO, J. M. et al. Filología y Didática Hispánica. Hamburg, Romanistik in Geschichte und Gegenwart, Band 1, Helmut Buske Verlag, 1975.

MAIA, C. A. História do galego-português. Coimbra: Imprensa da Universidade, 1986.

MARTÍNEZ, D. G.. A onomástica persoal na lírica medieval galego-portuguesa. In: AGRELO, A. I. B. Na nosa lyngoage galega: a emerxencia do galego como lingua escrita na Idade Media. Santiago de Compostela: Consello da Cultura Galega e Instituto da Lingua Galega, 2007.

MARTÍNEZ, M. L.; MOSCOSO MATO, E. Morfoloxía do Cancioneiro da Ajuda. In: AGRELO, A. I. B. Na nosa lyngoage galega: a emerxencia do galego como lingua escrita na Idade Media. Santiago de Compostela: Consello da Cultura Galega e Instituto da Lingua Galega, 2007.

MARTINS, K. C.; PAIVA, M. C. V-ra no português: uma análise diacrônica. Estudos Linguísticos, v. 42, n. 1, p. 540-552, 2013.

MASSINI-CAGLIARI, G.; FAVARO, G. S. Um estudo das formas verbais do pretérito perfeito do indicativo em português arcaico. Revista Eutomia - Ano III, v. 2, dez., 2010.

MONTEAGUDO, X. H. Historia social da lingua galega. Vigo: Galaxia, 1999. 
MONTEAGUDO, X.H.A Galiza e o espaço linguístico-cultural de expressão portuguesa. In: LOBO, T. et al. ROSAE: linguística histórica, história das línguas e outras histórias. Salvador: EDUFBA, p. 51-64, 2012.

MOURA, H. Relações paradigmáticas e sintagmáticas na interpretação de metáforas. Linguagem em (Dis)curso, v. 7, n. 3, p. 417-452, 2007.

PÉREZ, E. B. La expresión de la irrealidad en español. Moenia, v. 23, p. 95-146, 2017.

REICHENBACH, H. Elements of Symbolic Logic. New York: Macmillan Company, 1947.

ROJO, G. La temporalidade verbal en español. Verba. Anuario Gallego de Filología. Universidade de Santiago de Compostela, p. 68-149, 1974.

SWEETSER, E. E. From etymology to pragmatics: metaphorical and cultural aspects of semantic structure. Cambridge: Cambridge University Press, 1990.

SÖHRMAN, I. El pluscuamperfecto en las lenguas Românicas. In: GUNNEL, E.; LARS, F. Festival Romanistica. Contribuciones lingüisticas - Contributions linguistiques - Contributi linguistici - Contribuições linguísticas. Stockholm: Stockholm University Press, 2015.

TEYSSIER, P. História da língua portuguesa. Tradução de Celso Cunha. São Paulo: Martins Fontes, 1997.

TRAVAGLIA, L. C. Um estudo textual-discursivo do verbo no português do Brasil. 1991. Dissertação (Mestrado) - UNICAMP, Campinas, 1991.

VASCONCELOS, C. M. Cancioneiro da Ajuda, vol. II, Lisboa, Imprensa Nacional - Casa da Moeda, 1990 (reimpressão da edição de Halle, 1904).

XAVIER, M. F. Variação e mudança lexical no Português Medieval - o caso dos verbos. Domínios da Linguagem, v. 2, p. 225-242, 2009.

XOVE, X. A temporalidade verbal nas "cantigas d'escarnho e de mal dizer. Monografia Facultade de Filoloxia. Universidade de Santiago, 1977. 